from it in not being cusped, though otherwise imitating its general form.

It would appear, therefore, as if a wedge-shaped film of water were pushed ahead of the canoe, or other obstacle, the lower surface of which must, from the arrangement of the particles arrested, have been of rapidly-increasing curvature. Two diffculties, however, present themselves to this explanation-it is difficult to see how the film could have extended to the wave itself, as no particles, however small, appeared to be arrested within an inch or two of it; and my rec-Hection is that upon the occasion of my first examining the wave driven before my canoe, light objects merely resting upon the water, like thistle down, seemed to be not at all affected by it, but to pass on towards the canoe unimpeded. Such objects, however, are so easily affected by the wind, or tven the resistance of the air, that it was not easy to verify the observation.

Sume other facts may be mentioned. The depth of the obstrucison in the water seemed to have no sensible effect on the wave formed. Whether it was a $\log$ a foot through, or an inch board floating on the water, or whelher it was the middle of the canoe drawing five or six inches, or the bow and stern barely touching the surface, the effect seemed almost the same. I have often, indeed generally, failed in my attempts to generate a wave with a canoe, and although upon the occasion when I first saw it so formed, I could trace it at fully eight feet from the canoe, I never found such a wave naturally formed at anything like that distance. The explanation appears to be that ic requires very even and steady action to generate the wave; but that wisen once established it can be maintained under circumstances in which it would not be otherwise produced. As I' stated before, if you approach it in one direction, you may take a canoe over it and it emerges on the other side unimpaired; the irregular currents of an eddy have no effect upon it except to give it an undulating motion, and I have seen it maintaining its place amongst the standing waves of a rapid when they have becn several inches high. I have even raised considerable swells by rocking a canoe close to it, and it rides over them without disturbance; but the slightest ripple caused by the wind makes. it disappear in a moment ; and if spirits of turpentine be dropped on the water a little above it, the whole wave is instantly obliterated to a distance apparently far beyond that to which the oily film exrends.

Ottawa, Canada, Dec. 28, 1871

\section{The Rigidity of the Earth}

Althovgh, as he truly says, Sir W. Thomson's arguments for the rigidity of the earth have never been attacked, yet they have undoubtedly been too long ignored; and it is gratifying to see them asserted by their author in NaTURE. Allow me, however, to remark on one sentence near the end of his quotation from the "Natural Philosophy," where Mr. Hopkins's observation is given, that the distr:tution of fluid matter within the earth is "probably quite local." Unless I am mistaken, Mr. Hopkins's opinion was, that its distributi, n is, as one might say, fortuitous. But, as I have elsewhere observed, the trains of volcanoes which accompany many of the great lines of elevation for enormous distances re..der the motion of such local distringtion of fluid matter highly improbable, unless it be admitted that its presence is due to mountain elevations as a cause. I have suggested that this fluidity may arise from a diminished pressure beneath mountain ranges, owng to their mass being partly sup ported by the lateral thrust which has upraised them-a supposition which Mr. Scrope had already applied to account for an increased fluidity in the heared rock underlying a volcanic vent, when from any cause the pres.ure became less.

If any of your correspondents can propose another explanation of this remarkable coincidence compatible with the supposition of a rigid globe, it would be interesting to know it.

Harltun, Cambridge

O. FISHER

\section{English Rainfall}

IN reply to the letter of Mr. Vernon, in NATURE of the I8th inst., permit me to say that the confusion between the two Sealhwaites is his, not mine. In the article to which he ref rs there is not a word about either Cockley Bridge or the Valley of the Duddon. His top graphical knowledge of the districts is, apparently, as inexact as his manner of reading; for he does not seem aware that "the Stye," of which he speaks, is the name, not of a place, but of a rain-gauge, in, as I said before, the immediate neighbuurhood of Stockley Bridge.

\section{J. K. L.}

\section{Circumpolar Lands}

IN the last number of NAture (Jan. I8), Mr. J. J. Murphy asks, "Can any mathematical reason be a-signed why the contraction of the earth should be least in the direction of the polar direction? This would account for the rising of the land at the poles."

In the Proceedings of the Literary and Philosophical Society of Liverpool for Nov., 1857, there is a paper on a probable change in the earth's form, in which the rising of the land at the poles is inferred as a necessary result of the cooling and contraction of the earth.

The following is the substance, though not the exact words, of a porijon of the paper; the precise words would not be in. telligible without a diagram.

If a spheroid of equilibrium, in motion about an axis, contract uniformly in the direction of lines perpendicular to its surface, a new spheroid is produced, having a greater degree of eccentricity, because if equal portions are taken off the two diameters, the ratio of the equatorial to the polar diameter is increased. This is equivalent to a heaping up of matter around the equator in excess of what is due to the velocity of rotation, an increased pressure on the interior, in that region, must be produced, and a consequent transmission of pressure towards the poles. "A change of form is then necessary to restore equilibrium. This may not take place uniformly per gradum, fur if there be a resistance from a rigid external crust, the force must accumulate until it exceeds the resistance, and thus frequent adjustments per saltum may ensue. It is probable, therefore, that the earth's form is undergoing a slow progressive change."

Queen's College, Liverpool, Jan. 2I

GEORGE HAMIT TON

\section{The Kiltorkan Fossils}

Mr. BAILY's letter needs only a word or two from me. I must protest against my reference to an error made by Mr. Baily being considered a "personal attack" upon him, or an "accusation" against him. Has Mr. Baily ever consulted a systematic work which did not contain corrections of the real or supposed error; of former workers? And did he consider such corrections as "personal attacks"?

On two points Mr. Baily has misunderstood or misread the plain statements of my letter :- 1 . I did not say that his drawing in "Explanation of Sheets 187, \&c.," was made on the spot at Kiltorkan, but that it was a drawing of the fossil he had named Sagenaria Veltheimiana; 2. The qualifying phrase, "coal measure," was used, as it often is, as the equivalent of "carboniferous." How Mr. Baly could make it mean anything else perplexes me; seeing the Upper Carboniferous beds have no connection with the question. To have used it in the limited sense he suggests, and elaborately argues against, would bave been absurd.

The remainder of Mr. Baily's letter is occupied with reference to priva:e letters as evidence in the case. That written by $\mathrm{Mr}$. B.ily to Prof. Heer confirms the sratement I made at the Geological Society, and repeated in your pages; but, in as far as it declares that the specimens sent to Prof. Heer from Kiltorkan were named $S$. Bailyana, it differs from the statement made by Prof. Heer at the Geolorical Socicty, who, on the evidence of these fossils, included $S$. Veltheimiana among the Kilturkan fissils, and never mentioned S. Bailyana!

The reference to the oth:r privale letters is equally unhappy; for $\mathrm{Mr}$. Baily is quite wrong in supp:sing my "accusation" was made because I could not persuade him to join me in work. My letter, if he will look at it again, bears a date some time after the "accusation" was made. And if at the same time he will read his reply, he will find that the reason he gave for declining to work with me is somewhat different from those he records in your pages. But the fact is, the letters have nothing whatever to do with my declaration. now more than ever confirmed by Mr. Baily's letter, that his giving to the Irish Lepidodendroid plant the name of a carboniferuus species misled Prof. Heer. If Mr. Baily's letter indicates the "facts" contained in his paper, I can only conclude that it was the patriotism of your reporter that induced him to characterise $\begin{array}{ll}\text { them ầs "strong." } & \text { W. CARRuTHers }\end{array}$ 